\title{
APPLICATION OF AIR DISPERSION MODELLING FOR EXPOSURE ASSESSMENT FROM PARTICULATE MATTER POLLUTION IN MEGA CITY DELHI
}

\author{
Shweta Bhati*, Manju Mohan* ${ }^{1}$ Archana Rao** \\ ${ }^{*}$ Centre for Atmospheric Sciences, Indian Institute of Technology, Delhi, India; \\ ${ }^{* *}$ Tata Consultancy Services, India
}

\begin{abstract}
An attempt has been made to apply air dispersion modeling for exposure assessment of particulate matter in terms of mortality change. Ambient particulate matter concentrations have been estimated by AERMOD (07026) for the year 2004 in Delhi, India. Concentration output has been obtained for all sources as well as individual source category. It has been found that though the model has a tendency towards under-prediction, estimated concentration values agree with the observed concentrations within factor of two. The transport sector shows highest contribution towards particulate matter pollution. Model results have been used to analyse mortality change associated with two hypothetical emission reduction scenarios in vehicular traffic emissions and thermal power plants. The results from the exposure assessment study highlighted the significance of reduction in vehicular emissions in controlling particulate matter pollution in Delhi.
\end{abstract}

Key words: Air Pollution Modeling, Model Evaluation, Particulate Matter, Regulatory Models, Exposure Assessment, Health Risk Analysis

\section{INTRODUCTION}

Delhi has been designated as an air pollution control area by Ministry of Environment and Forests, Government of India in recognition of the severity of air pollution due to vehicular, industrial and domestic sources (MoEF, 1998). In a mega city like Delhi where more than 1,00,000 petrol and diesel based vehicles are added every year to the roads (DES, 2006), air quality management in terms of particulate matter (PM) becomes an area of significant concern.

Exposure assessment studies based on pollution monitoring networks face certain limitations (Bell, 2006) in terms of inadequate representation of individual or community-level exposure and inability to provide full temporal and spatial coverage. The present study evaluates the performance of USEPA regulatory model AERMOD (07026) for modeling concentrations of total suspended particulate matter in Delhi for the year 2004. The annual average concentration estimates from the model have been applied to Ostro Dose Response Equations (Ostro, 1994) for assessing health effects in terms of change in mortality. The capital city of Delhi is located at $28^{0} 38^{\prime} 17^{\prime \prime} \mathrm{N}$ and $77^{0} 15^{\prime} 51^{\prime \prime} \mathrm{E}$ with an altitude of $215 \mathrm{~m}$ above sea level. Delhi has three distinct seasons of summer (March - May), monsoon (July, August, and September) and winter (November - February). The Central Pollution Control Board (CPCB), the governmental nodal agency responsible for monitoring and regulating the pollution scenario, measures the particulate matter concentration at seven monitoring stations in Delhi. Five of these are located in residential areas. The other two constitute of an industrial area and one of the busiest traffic intersections of Delhi.

\section{MATERIALS AND METHODS}

\subsection{Applied Model and Source, Receptor and Output Options}

AERMOD (version 07026), was developed by the U.S Environmental Protection Agency and is used for pollutant concentration from point, line and area sources. Particulate matter emissions mainly arise from three sources: Transportation Sector, Power plants, and other sources which includes domestic and waste sector. Emissions from Power plants have been considered under point source options while emissions from transportation and other sectors have been modeled under area sources. In the present study, a grid network was constructed which comprised of 173 cells $(2 \mathrm{~km} \times 2 \mathrm{~km})$ covering $26 \times 30 \mathrm{sq} \mathrm{km}$ area of Delhi, where most of the urban activities take place. Particulate matter emissions for the year 2004 from the sectors such as transportation (CPCB, 2006), Power plants (CEA, 2006) and other i.e. domestic and waste etc. (DES, 2006) sources were calculated for each

\footnotetext{
${ }^{1}$ Corresponding Author: Manju Mohan, Centre for Atmospheric Sciences, Indian Institute of Technology - Delhi, Hauz Khas, New Delhi - 110016, India. email: mmohan65@yahoo.com
} 
grid cell. The methodology to obtain total emission estimates was based on an earlier work by Gurjar et al, 2004. Methodology for the preparation of the gridded emission inventory is based on an earlier work by Mohan et al, 2007. The model was run over the entire grid network of Delhi. The output was generated in form of 24 hour average and annual average total suspended particulate matter concentrations.

\subsection{Model Evaluation}

The monitored daily averaged air quality data for the year 2004 of seven stations in the city was used for comparison with the model results and the analysis of the monthly data was done. Statistical performance measures were used to evaluate the performance of the model. The evaluation of performance of model was based on various statistical measures (Hanna et al, 1993, Mohan et al., 1995).

\subsection{Exposure Assessment}

The health effects of particulate matter pollution range over a wide variety of symptoms but death is the most clearly defined health end point. In this study, Dose- response equation developed by Ostro (1994) has been used to estimate change in mortality cases in different scenarios. The equation has an advantage in this study in terms of being applicable for ambient $\mathrm{PM}_{10}$ concentration rather than personal $\mathrm{PM}_{10}$ exposure values. $\mathrm{A}$ translation factor of 0.53 (CPCB, 2005) is taken for $\mathrm{PM}_{10} / \mathrm{TSP}$ (Total Suspended Particulate) for Delhi conditions.

\section{RESULTS AND DISCUSSIONS}

\subsection{Overall Performance of AERMOD}

Most results from AERMOD agreed with the measured concentration statistics to within a factor of two (Figure 1). The statistical parameters also satisfied model reliability criteria laid out in earlier studies (Chang et al, 2004; Kumar et al., 1993). Satisfactory values for Correlation Coefficient and Index of agreement indicated that the predicted values followed the trend of the observed values. Greater prevalence of positive Fractional Bias values for all the sites indicated that the model has a tendency towards under-prediction as compared to observed values (Mohan et al, 2008). Under-prediction of the model is revealed further in Quantile - Quantile Plots (Figure 2).

Often emission inventory find it difficult to suitably account for all emission sources of a pollutant and this may affect the model bias. The total suspended particulate matter concentration in Delhi gets affected at times by long range transport of dust by dust-storms due to its close proximity to desert land in the nearby state of Rajasthan. Such random and irregular phenomenon is not being accounted for in the emission inventory presently. Also, polluting industries in Delhi were relocated in accordance with Supreme Court ruling in year 2000. However, certain small factories are still expected to be operational within city boundary limits. Another important reason is that, the activities under sectors such as transport and domestic, which lead to particulate matter emissions, are under the purview of regulatory authorities and hence a close estimate of total emissions from these sectors can be obtained. Though emissions from these sections are significant but their quantitative estimation is based on many assumptions (Kandlikar and Ramachandran, 2000, Gurjar et al 2004). The monitored ambient data, however, would measure concentration due to all sources and thus observed concentrations are usually higher than those estimated by models.

Annual average total suspended particulate matter concentrations was calculated by averaging concentration output of each grid cell of the entire study area of Delhi, obtained from the model estimates when the model was run for each source category separately. Transportation Sector had the greatest contribution ( 66.4 \%) towards total particulate matter concentration followed by Domestic and waste $(\sim 30.8 \%)$ and Power plants $(\sim 2.7 \%)$. Ground level concentration due to power plants is usually low as they are elevated sources. The small contribution of power plants towards total ambient particulate matter contribution can also be attributed to implementation of better environmental management policies. The transport sector has the greatest contribution owing enormous increase in number of diesel and petrol based vehicles. 


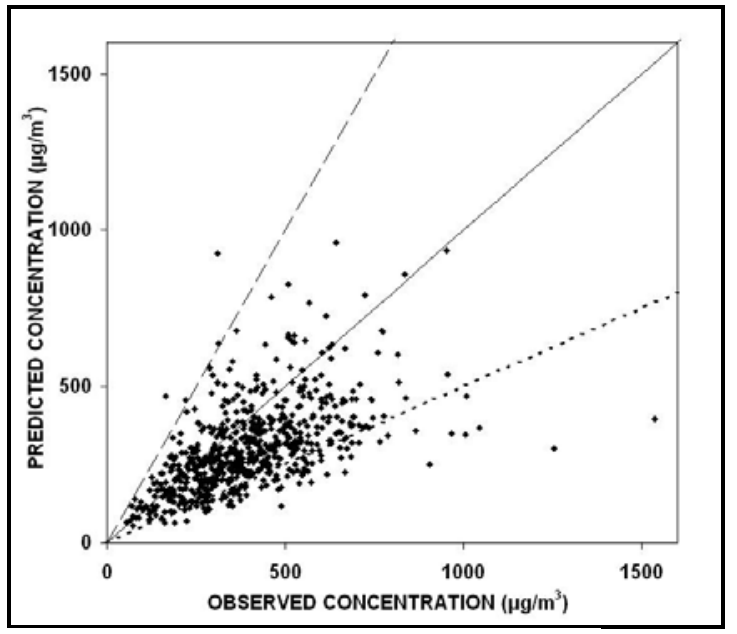

Figure 1: Scatter Plot of Observed and Estimated Daily Average PM Concentrations

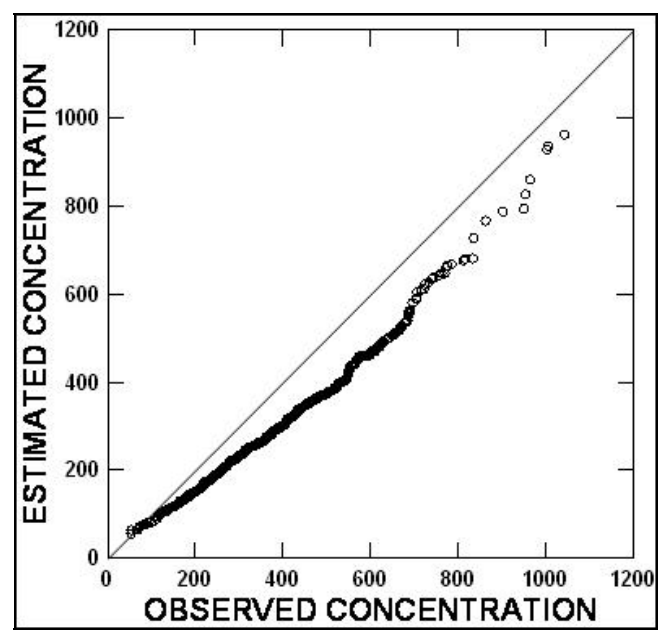

Figure 2: Q-Q Plot of Estimated and Observed PM Concentrations $\left(\mu \mathrm{gm}^{-3}\right)$

\subsection{Exposure Assessment}

In this study, exposure assessment has been conducted from the view point of change in mortality associated with change in particulate matter concentration. Considering the availability of the required data, particulate matter - mortality relationship equation developed by Ostro, 1994 has been used to estimate change in mortality in two scenarios:

\section{Case 1: Change of production of power from coal based sources to Natural Gas:}

Replacement of fuel from coal to natural gas leads to significant reduction in SPM (suspended particulate matter) which would subsequently reduce the $\mathrm{PM}_{10}$ as well. This case study demonstrates the effect of this control measure on overall reduction in the expected mortality. Total fuel consumption by the three coal based power plants in Delhi ranges from 4777-5923 Kilotons to generate about $6253 \mathrm{GWh}$ of electric power. Natural Gas is a clean fuel and thus particulate matter emissions from gas based power plant are greatly reduced. Assuming that total electric energy is generated using Natural Gas as fuel, the decrease in Particulate Matter emissions is approximately estimated out to be $94 \%$ based on an earlier study by Gurjar et al, 2004. Considering $94 \%$ reduction in emissions from the power sector, total particulate matter concentrations were estimated for each cell of the study area. Change in mortality was then estimated using Ostro's equation which yielded a change of 482 deaths per year in this scenario. Thus a decrease of 482 deaths per year can be expected if there is a complete shift from coal based power production to gas based power production.

\section{Case 2: $20 \%$ decrease in emissions from Transportation Sector.}

Increased use of public transport like CNG (Compressed Natural Gas) buses and Metro Rails will result in a decrease from emissions from sources like motor cycles and petrol and diesel based cars. However, since estimation of actual change in emissions due to such a shift in use of public transport was outside the scope of this study, a conservative decrease of $20 \%$ in emissions from transport sector has been taken up as a case. The decrease in the number of mortality cases was estimated at 2527. In other words if an efficient and less polluting public transport system leads to a decrease of $20 \%$ in ambient particulate matter levels, we can expect a reduction of about 2527 deaths per year in the city.

These calculations are based on averaged data and many assumptions; hence the results might not represent the exact figures in reality. These calculations were done on the basis of short-term immediate effects of the pollutant and taking the whole population into account. Nevertheless, it is clear from the results of Case 1 and 2 that it is emissions from the transport sector in Delhi which need consideration for reduction in terms of particulate matter pollution from the viewpoint of public health. Reductions of about $94 \%$ emissions from Power plants due to switch over to a cleaner fuel leads to a decrease of 482 deaths per year. Whereas, $20 \%$ reduction in transport emissions leads to a decrease of about 2527 deaths, that is, about five times greater decrease in mortality as compared to Case 1.

There is always an uncertainty associated with such dose response relationships. The ratio of $\mathrm{PM}_{10} / \mathrm{TSP}$ keeps on varying and its estimation is also based on many assumptions. We can rely on model results only if we are confirmed about accuracy of our emission input. Mortality is a complex phenomenon which cannot be attributed to 
a handful of parameters. Change in mortality in different scenarios taken above assumes that while one scenario changes, all other aspects of urban activities leading to particulate matter pollution remain constant. Possibility of such an assumption to be true in actual conditions is again very remote. However, in the present study, we have made an attempt to integrate air quality modeling with health risk analysis to assess their application for formulation of air quality management strategies and this first attempt has given a reasonable estimate of scenarios.

\section{CONCLUSIONS}

- Overall, the performance of AERMOD for estimation of particulate matter concentration was rated as satisfactory for Delhi considering results of statistical parameters.

- Vehicular emissions have been found to be the greatest contributor towards ambient particulate matter pollution followed by others (i.e. domestic and waste) and the power plants.

- A hypothetical case specific mortality assessment revealed that a small decrease in vehicular emissions leads to five times greater reduction in mortality count as compared to a major shift from coal to natural gas sources in power production sector.

- The results of exposure assessment highlight the impact of control measures of important vehicular emission sector towards total particulate matter concentration and consequent health benefits in the city.

\section{References}

- $\quad$ Bell, M.L., 2006. The use of ambient air quality modeling to estimate individual and population exposure for human health research: A case study of ozone in the Northern Georgia Region of the United States, Environment International, 32, 586-593.

- Central Electricity Authority (CEA), 2006. All India Electricity Statistics: General Review 2006, Ministry Of Power, Government of India.

- $\quad$ Central Pollution Control Board (CPCB), 2005, Annual Report 2004-2005 .

- Central Pollution Control Board (CPCB), 2006. Vehicular Air Pollution in Delhi-A Preliminary Study, Government of India, 2006

- Chang, J.C., Hanna, S.R., 2004. Air quality model performance evaluation, Meteorology and Atmospheric Physics, 87, 167-196.

- Directorate of Economics \& Statistics (DES), Delhi Statistical Handbook- 2006, Govt. of NCT of Delhi.

- Gurjar, B.R., van Aardenne, J.A., Lelieveld, J., Mohan, M., 2004. Emission estimates and trends (1990-2000) for megacity Delhi and implications, Atmospheric Environment, 38, 5663-5681.

- Hanna, S.R., Chang, J.C., Strimaitis, D.G., 1993. Hazardous Gas Model Evaluation with Field Observations, Atmospheric Environment, 27A, 2265-2285.

- Kandlikar, M., Ramachandran, G., 2000. The causes and consequences of particulate air pollution in urban India: A synthesis of the science, Annual Review of Energy and Environment, 25, 629-684.

- Kumar, A., Luo, J., Bennett, G., 1993. Statistical evaluation of lower flammability distance (LFD) using four hazardous release models, Process Safety Progress, 12, 1-11.

- Ministry of Environment \& Forests (MoEF), 1998. White Paper on Pollution in Delhi with an Action Plan, 1998, Government of India.

- Mohan, M. Panwar, T.S., Singh, M.P., 1995. Development of dense gas dispersion model for emergency preparedness, Atmospheric Environment, 29, 2075-2087.

- Mohan, M., Bhati, S., Archana, S., 2008. Performance Evaluation of AERMOD and ADMS-Urban for Total suspended Particulate Matter Concentrations in Megacity Delhi, International Workshop on Regional and International Transport of Air Pollution, TF-HTAP, Washington DC

- Mohan, M., Dagar, L., Gurjar, B.R., 2007. Preparation and Validation of Gridded Emission Inventory of Criteria Air Pollutants and Identification of Emission Hotspots for Megacity Delhi, Environmental Monitoring and Assessment, 130, 323-339.

- Ostro, B., 1994. Estimating the Health Effects of Air Pollutants: A Method with an Application to Jakarta, Policy Research Working Paper no. 1301, World Bank, Washington, DC. 